\title{
Tests of encoding tradeoffs between item and associative information
}

\author{
WILLIAM E. HOCKIEY and CAROLINA CRISTI \\ Wilfrid Laurier University, Waterloo, Ontario, Canada
}

\begin{abstract}
The assumption that item and associative information are processed separately and that there is a tradeoff in the amount of each type of information that can be encoded in a given study interval (e.g. Anderson \& Bower, 1972; Murdock, 1982, 1992) was examined. When item information was emphasized at study, recognition memory for associative information was poor, demonstrating that item information can be emphasized over associative information. In contrast, when associative information was emphasized, associative recognition greatly improved but item recognition did not suffer. This pattern of results was found at both fast and slow presentation rates, and for both high and low word concreteness and word frequency. Measures of confidence and response latency were also consistent with this pattern. Thus, the encoding of associative information did not measurably diminish item recognition performance.
\end{abstract}

Item information represents the occurrence of an item, whereas associative information represents relationships between events (Humphreys, 1976, 1978; Murdock, 1974). This distinction has been supported by several recent findings. For example, Dosher (1988) and Gronlund and Ratcliff (1989) have shown that the retrieval of item and associative information have different time courses. Hockley (1991, 1992; Murdock \& Hockley, 1989) demonstrated that item and associative information differ in their rate of forgetting, or susceptibility to interference from intervening events. Finally, Clark (1992; Clark \& Burchett, 1994; Clark \& Shiffrin, 1992) and Hockley (1994) have shown that natural language word frequency has a differential effect on item and associative recognition performance.

Hunt and his colleagues (Einstein \& Hunt, 1980; Hunt \& Einstein, 1981; Hunt \& Seta, 1984) have argued that individual-item processing involves the encoding of itemspecific information that serves to enhance discriminative processes. Relational processing, on the other hand, involves the encoding of similarities among events that serves to enhance retrieval processes. The distinction between these two types of information, or two encoding processes, has been shown to be important in accounting for a variety of aspects of memory performance. These

\footnotetext{
This work was supported by a Natural Sciences and Engineering Research Council of Canada operating grant to the first author, and an NSERC summer research scholarship awarded to the second author. C.C. is now at the University of Western Ontario. We thank Ben Murdock for helpful suggestions and his encouragement to pursue this study, and Steve Clark, Doug Nelson, Robert Crowder, Tim Curran, and Doug Hintzman for their constructive comments on earlier versions of this paper. We also gratefully acknowledge the able assistance of Chris Jeens and Robert MacDonald in data collection. Correspondence can be addressed to W. E. Hockley, Department of Psychology, Wilfrid Laurier University, Waterloo, ON, Canada N2L 3C5 (e-mail: whockley@mach1.wlu.ca).
}

aspects include the relationship between recall and clustering (Einstein \& Hunt, 1980), typicality effects in recall (Hunt \& Einstein, 1981), category size effects in recall (Hunt \& Seta, 1984), the concrete word advantage in recall (Marschark \& Hunt, 1989), hypermnesia (Burns, 1993; Klein, Loftus, Kihlstrom, \& Aseron, 1989), the generation effect (Hirshman \& Bjork, 1988), and priming effects in recognition memory (Dosher, 1991).

If item and associative or relational information are distinct and serve different memorial functions, as the preceding studies indicate, is it the case that item and associative information are encoded separately? Can subjects, when presented with two or three unrelated words, process the items individually and not encode any association between them? In Experiment 1 of Glenberg, Smith, and Green (1977), participants rehearsed three words together in rote fashion as a distractor task. An unexpected recall test did not show any evidence that associations were formed between words rehearsed 1,3 , or 9 times together. Overall levels of recall, however, were quite modest.

The results of Glenberg et al. (1977) suggest that itemspecific processing can be distinct from associative processing. Is the reverse also possible? Is associative processing separate or distinct from item-specific processing? It seems obvious that in order to form an association or relationship between two items, the items themselves must first be processed. But after the items have been initially encoded, is the subsequent processing of associative information distinct from the processing of item- specific information? In other words, is there a tradeoff between the encoding of item-specific and associative information?

\section{Encoding Tradeoff}

The question of whether there is an encoding tradeoff between item and associative information can be illustrated by considering a situation in which a subject is given 
limited time to study a pair of unrelated words. If the subject spends more encoding time in processing itemspecific information, there would be less time available to process associative information. In such a situation it would be expected that more item information would be encoded than associative information. Conversely, if the subject spends more time in processing associative information, and therefore less time in processing itemspecific information, would it be the case that more associative information than item information would be encoded? Would memory for item information be greater in the former situation than in the latter? The question of a tradeoff between the encoding of item and associative information presupposes that item and associative information are processed and retrieved separately and that time spent in encoding one type of information is at the expense of the processing of the other type of information.

Clark and Shiffrin (1992) have hypothesized that item and associative information are stored at different rates, and that it takes more time to encode associative information than it does to encode item information. In two experiments, they varied presentation rate and included tests of single item recognition and associative recognition. They found that both item and associative recognition performance increased with increasing presentation rate, and, consistent with their hypothesis, they found in one experiment that the increase in presentation rate produced a greater increase in associative recognition performance than in item recognition performance. If item and associative information are processed at different rates, and if the rate for associative information is slower, it would seem quite possible that there is an encoding tradeoff between item and associative information.

Anderson and Bower (1972) were, perhaps, the first to formally propose an encoding tradeoff between item and associative information. In their view, item information is represented by the tagging or marking of nodes in longterm memory, and relationships between items are represented by tagged pathways between nodes. Anderson and Bower also assumed that the tagging of nodes and pathways are independent processes and that processing resources are limited. These assumptions predict that the tagging, or encoding, of one type of information is at the expense of the encoding of the other type of information.

The assumption that there is an encoding tradeoff between item and association information has also been incorporated in many recent applications of Murdock's (1982) theory of distributed associative memory (TODAM) model. In TODAM, both item and associative information are stored in a common memory vector. For item information, a vector representing the encoded attributes of the item is simply added to the memory vector. For associative information, the relationship between two items is represented by the convolution of the two separate item vectors. Thus, given the pair $A B$, three separate vectors, $\mathbf{a}, \mathbf{b}$, and the convolution of the two item vectors, $\mathbf{a} * \mathbf{b}$, would be added to the memory vector.
At test, item and associative information are retrieved separately. Given the encoding of the pair $A B$, recognition of A, B, or the association between A and B is accomplished by computing the dot product between the probe vector $(\mathbf{a}, \mathbf{b}$, or $\mathbf{a} * \mathbf{b})$ and the memory vector. The dot product provides a global measure of the strength of the match between the contents of the probe vector and the contents of the memory vector.

In the original development of TODAM (Murdock, 1982,1983 ) three separate weighting parameters were used to represent the encoding of the A and $B$ members of the pair and the association between the members of the pair. The weighting coefficients are "attentional" parameters that denote the amount of attention paid to each individual item (A and B) and to the A-B association. The finding of an encoding tradeoff between item and associative information would provide empirical support for the assumption that item and associative information can have different "attentional" weights.

In later applications of TODAM (e.g., Lewandowsky \& Li, 1993, 1994; Lewandowsky \& Murdock, 1989; Murdock, 1987, 1989, 1992; Murdock \& Hockley, 1989; Weber, 1988), it has been assumed that the weights for item and associative information sum to one (i.e., $w(\mathbf{a} * \mathbf{b})=$ $1-[w(\mathbf{a})+w(\mathbf{b})])$. This "limited-capacity assumption" (Murdock, 1992) of TODAM makes the strong prediction of a tradeoff between the encoding of item and associative information because their weighting coefficients are negatively correlated.

Evidence that supports the assumption that there is an encoding tradeoff between item and associative information is, however, limited and equivocal. Previous research that bears on the question of a tradeoff has been quite mixed. These studies are considered below.

\section{Previous Research}

Studies that have examined the effects of test expectancy on recall and recognition performance provide a potential test of an encoding tradeoff. In these studies, participants were led to expect either a recall or a recognition test prior to study and then were given either the expected or the unexpected test. It is generally assumed that participants expecting a recall test will engage in more organizationally oriented processing and that those expecting a recognition test will emphasize individual items. If such is the case, then, according to the encoding tradeoff hypothesis, recall should be greater in the recall-expectancy condition and item recognition should be higher in the recognition-expectancy condition.

This pattern of results, however, has not been obtained. Although recall is typically higher in the recallexpectancy condition than in the recognition-expectancy condition, item recognition performance in the two conditions has been found not to differ (e.g., Connor, 1977; May \& Sande, 1982) or has been found to be higher in the recall-expectancy condition (e.g., Balota \& Neely, 1980; Neely \& Balota, 1981). One problem with studies 
of this nature, however, is that it is not clear what encoding strategies participants use in the two expectancy conditions. Furthermore, in recall, both item and relational information are important. Einstein and Hunt (1980; Hunt \& Einstein, 1981) have shown that item-specific and relational processing, when combined, produce greater recall than does either type of processing alone. Thus, the optimum strategy for participants in the recallexpectancy condition is to encode both item and relational information.

Studies that have compared the effects of separate with those of interactive imagery on memory for word pairs provide a situation in which encoding strategy is controlled. Imagery has been shown to be beneficial for recognition of individual items, and interactive imagery is a very effective strategy to associate or relate individual items (e.g., Bower \& Winzenz, 1970; Dempster \& Rowher, 1974). Several studies have demonstrated that cued recall and pair recognition are greater following interactive rather than separate imagery, whereas item recognition is better for words imagined separately than for words imagined interactively (Bain \& Humphreys, 1988; Begg, 1979; McGee, 1980). In addition, Begg, Maxwell, Mitterer, and Harris (1986) found that judgments of item frequency were more accurate for separately imagined items than for items that were imagined interactively. These results suggest a tradeoff between the encoding of item and associative information. Indeed, Begg (1979) stated:

By and large, then, integrated processing does lead to some loss of recognizability of single items.... Thus, joint processing, if it is accomplished in a truly integrated fashion, may lead to a tradeoff in which items are highly accessible once cues are recognized, but in which those cues are somewhat less likely to be recognized. (p. 121)

Similarly, Bain and Humphreys (1988) suggested that "item and relational information tradeoff in opposing ways during image formation" (p. 118).

In other similar studies, however, item recognition has been found to be equally good after separate and interactive imagery (Begg, 1978, Begg \& Sikich, 1984; Bower, 1970; Dempster \& Rowher, 1974). The reason for these conflicting results is not clear. In all of these studies, the stimuli were common concrete nouns and participants were given similar instructions in the separate and interactive imagery conditions. In all but two of the studies, participants were given $5 \mathrm{sec}$ to separately imagine each word and $10 \mathrm{sec}$ to imagine pairs of words together. (The two exceptions are Begg et al., 1986, and Begg \& Sikich, 1984 , where the presentation rate was 5 sec per pair.) Given such relatively long study intervals, participants in the interactive condition may have had sufficient time to encode both item and associative information. Also, participants were given only very limited practice on the instructed strategy. Thus, they may not have always been able to optimize their encoding of the emphasized information, or may not always have been able to restrict their encoding to the emphasized information.
As the preceding review indicates, evidence for an encoding tradeoff between item and associative information is equivocal. These studies, though, were not designed specifically to test for such a tradeoff. The present study was designed with this purpose in mind.

\section{Tests of Encoding Tradeoffs}

Participants were presented with a series of different lists of random pairs of words. One group of participants was instructed to emphasize memory for the individual items, and every study list was immediately followed by an item recognition test. A second group was instructed to emphasize associations between the words of each pair, and each study list was followed by an associative recognition test. The immediate tests were designed to encourage and reinforce the encoding of the emphasized information, and participants were also given feedback on the number of correct responses following each immediate test. In an unexpected final recognition test, all participants were tested for recognition of both item and associative information from all of the study lists. Evidence for an encoding tradeoff between item and associative information would be obtained if, on the final test, associative recognition was higher for the associative emphasis group and item recognition was greater for the item emphasis group.

Memory for item and memory for associative information were both evaluated using recognition tests. Associative recognition provides a relatively pure test of memory for the relationships between events in that, unlike free or cued recall, it does not require memory for the individual items. In this procedure, subjects study a list of random word pairs that can be represented as $A B$, $\mathrm{CD}, \mathrm{EF}, \mathrm{GH}, \ldots \mathrm{MN}$. Tests of item recognition involve distinguishing between words presented in the study list (A) and new words that have not been studied (X). Associative recognition requires discriminating intact or studied pairs (CD) from rearranged test pairs (e.g., EH). Note that rearranged pairs, like intact test pairs, consist of two old or studied words. Therefore, the discrimination of intact and rearranged pairs cannot be based on memory for the individual items of the test pairs, but must be made solely on the basis of memory for the associations formed between items at study.

In the following experiments, participants studied different lists of word pairs with instructions to remember either the individual words or the word pairs. In Experiment 1 , a relatively fast presentation rate was used in an attempt to restrict encoding time to the emphasized information. A tradeoff was found when item information was emphasized, but no encoding tradeoff was observed when associative information was emphasized. The subsequent experiments were designed to establish the generality of this finding. In Experiments 2 and 3, presentation rate was varied. In Experiments 4 and 5, two different stimulus variables (word concreteness and word frequency) were manipulated. Finally, in Experiment 6 the effects of different associative strategies on recognition memory for item and associative information were evaluated. 


\section{EXPERIMENT 1}

\section{Method}

Participants. Forty introductory psychology students participated for course credit. Twenty students were randomly assigned to the item emphasis group and 20 to the associative emphasis group.

Apparatus and Stimuli. In all the experiments, list generation, presentation, and response recording were controlled by personal computers. The keyboards were fitted with an opaque plastic cover that exposed the labeled response keys.

The word pool used for Experiments 1 and 2 consisted of 480 concrete nouns derived from Paivio, Yuille, and Madigan (1968). On the basis of the Paivio et al. norms, where words are rated from 1 to 7 , all words in the word pool had an imageability rating of 5.00 or above.

Procedure. Every participant completed one session. A session consisted of six different study-test trials followed by a final recognition test. Study lists consisted of 30 critical pairs plus 2 primacy and 2 recency buffer pairs, for a total list length of 34 pairs. Pairs were constructed by randomly selecting (without replacement within each session) two words from the word pool. Each study pair was presented in the center of the monitor for $1.5 \mathrm{sec}$ with a 500 msec blank interval between presentations. A cue (?LEFT/RIGHT?) presented for $3 \mathrm{sec}$ indicated the end of the study list and was followed by the first of six test presentations.

The item emphasis group was instructed to study the words of each pair individually in preparation for an item recognition test. These participants were encouraged to form separate images or to generate a separate sentence for each word. The association emphasis group was instructed to study the pairs of words in preparation for an associative recognition test. In order to remember which words were presented together, participants were encouraged to form interactive images of the two words of each pair, or generate a sentence that included both words of each study pair.

For the item emphasis group, the immediate test list consisted of six two-alternative forced-choice item tests. Two test words were obtained from each third of the study list; one of the two tests consisted of the left member of a study pair, and one test consisted of the right member of a study pair. The new test alternatives were randomly selected from the word pool. The old and new test alternatives were presented in the middle of the screen with one word to the right of center and one word to the left of center. The leftright order of the old and new words was randomly determined for every test presentation.

For the association emphasis group, the immediate test list consisted of six two-alternative forced-choice associative tests. Associative recognition tests require the discrimination of intact (same or old) pairs from rearranged (new) pairs. Two intact pairs and two rearranged pairs were obtained from each third of the study list. The two rearranged pairs from each third of the study list were formed by pairing the left member of one pair with the right member of another pair. Thus, the left-right presentation order of the individual words in the study pairs was preserved in both the intact and rearranged test pairs. The intact and rearranged test pairs in each forced-choice comparison were from the same third of the study list. One test pair was presented to the right of the center of the screen, and one test pair was presented to the left of the center of the screen. The left-right order of the intact and rearranged test pairs was randomly determined.

In both conditions, the order of test presentations was random and the test list was subject paced. There was a 1-sec blank interval between a response and the presentation of the next test. Participants pressed the " $Z$ " key on the left of the keyboard to indicate that the target was on the left side of the screen, and the "/" key on the right of the keyboard to indicate that the target was on the right. All participants were encouraged to emphasize accuracy, and they received feedback on the number of correct responses after each immediate test list.
Participants were not informed of the final recognition test until they had completed the six study-test trials. For both groups, the final recognition test consisted of 6 item and 6 associative forcedchoice comparisons from each study list for a total of 72 tests. The final recognition item and associative tests were constructed in the same manner as were the immediate tests. That is, two single words, and two intact and two rearranged pairs, were obtained from each third of each study list. The intact and rearranged pairs in each forced-choice comparison were from the same third of the same study list. The words and pairs on the final recognition test had not been presented in the immediate tests. The order of tests was random and was subject paced.

\section{Results and Discussion}

On the immediate tests, the group emphasizing items correctly identified old single words as well as the group emphasizing associations correctly recognized intact pairs. The mean proportions of correct responses were .83 and .82 , respectively.

The mean proportions of items and associations correctly identified on the final recognition test for each encoding emphasis group are presented in Figure 1. A 2 (emphasize items or associations) $\times 2$ (item or associative recognition test) mixed factorial analysis of variance (ANOVA) was performed on the subject mean proportions. (The .05 level of significance was used to interpret all statistical comparisons.) The main effects of emphasis instructions $\left[F(1,38)=5.06, M S_{\mathrm{e}}=.03\right]$ and type of test $\left[F(1,38)=13.17, M S_{\mathrm{e}}=.01\right]$ were statistically reliable. The interaction between these factors was also highly significant $\left[F(1,38)=20.11, M S_{\mathrm{e}}=.01\right]$.

As can be clearly seen in Figure 1, when participants emphasized individual items, memory for associations between items was quite poor. When participants emphasized associations between items, recognition memory for associations was much more accurate. Thus, emphasis instructions strongly influenced memory for associations. In contrast, recognition memory for the individual items was as good for participants who emphasized associations as for participants who emphasized only items. Thus, the results of Experiment 1 do not show any

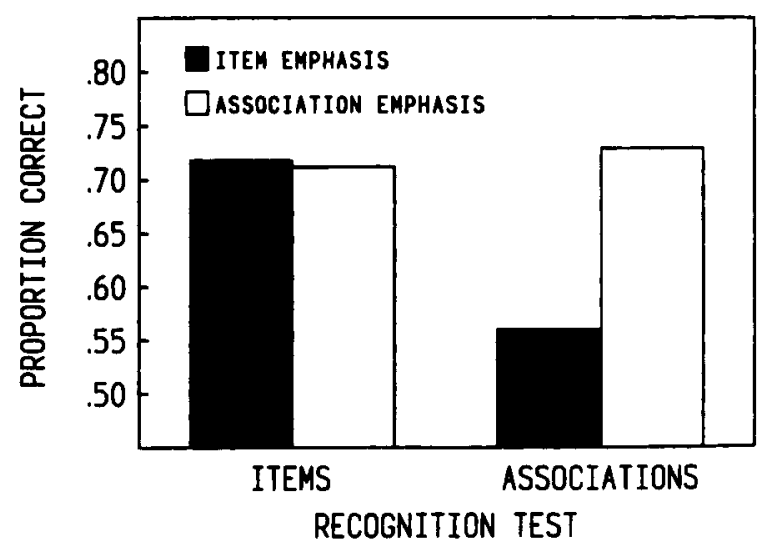

Figure 1. Mean proportion of items and associations recognized in the item and associative information emphasis conditions of Experiment 1. 
evidence of a tradeoff between the encoding of item and associative information when associative information is emphasized.

A relatively fast presentation rate was used in Experiment 1 in order to limit available study time to the emphasized information. However, as was noted in the introduction, Clark and Shiffrin (1992) have argued that item and associative information are encoded at different rates, and that it takes more time to encode associative information than it does to encode item information. If it takes longer to encode associative information than item information, then the $1.5-\mathrm{sec} /$ pair presentation rate used in Experiment 1 may not have allowed sufficient time for subjects to emphasize the encoding of associative information over item information. Experiment 2 was a replication of Experiment 1 that included a manipulation of presentation rate. Pairs were presented at either a $1.5-\mathrm{sec}$ or a $3-\mathrm{sec}$ rate in order to determine whether a tradeoff between item and associative information could be shown for the association emphasis group at a slower presentation rate. Presentation rate was varied between lists, rather than within lists, in order to prevent rehearsal borrowing between items presented at different rates (see, e.g., Yonelinas, Hockley, \& Murdock, 1992).

\section{EXPERIMENT 2}

\section{Method}

Participants. Forty students participated for course credit or for payment. Twenty students were randomly assigned to each emphasis condition.

Procedure. The procedure was identical to that of Experiment 1, with the exception of the presentation rate manipulation. For three lists, study pairs were presented at a 1.5 -sec rate (as in Experiment 1 ), and for three lists study pairs were presented at a 3sec rate. The order of lists was randomly determined in each session.

\section{Results and Discussion}

The mean proportions of correct responses on the immediate tests at the 1.5 - and $3-\mathrm{sec}$ presentation rates were .83 and .88 , respectively, for the item emphasis group, and .82 and .93 , respectively, for the association emphasis group. A 2 (items versus associative recognition) $\times 2$ (presentation rate) mixed factor ANOVA based on the subject mean proportions showed that the main effect of type of test was not significant $[F(1,38)<1]$. The main effect of presentation rate was highly significant $[F(1,38)$ $\left.=19.46, M S_{\mathrm{e}}=.01\right]$. Thus, slowing the presentation rate improved both item and associative recognition performance. The absolute increase in accuracy with the increase in presentation rate was greater for associative recognition than for item recognition, but the interaction between type of test and presentation rate was not statistically reliable $\left[F(1,38)=2.49, M S_{\mathrm{e}}=.01\right]$.

The proportions of correct responses for items and associations for each presentation rate for each emphasis group on the final recognition test are presented in Figure 2 . A 2 (emphasis condition) $\times 2$ (item vs. associative tests) $\times 2$ (presentation rate) mixed factor ANOVA was performed on the subject mean proportions from the final recognition test. The main effect of emphasizing items or associations $\left[F(1,38)=14.02, M S_{\mathrm{e}}=.03\right]$ and the main effect of presentation rate $\left[F(1,38)=19.28, M S_{\mathrm{e}}=.01\right]$ were both highly significant. The main effect of type of test (item or associative) was not reliable $[F(1,38)=1.66$, $\left.M S_{\mathrm{e}}=.01\right]$, but the interaction between type of test and emphasis condition was highly significant $[F(1,38)=$ $\left.14.90, M S_{\mathrm{e}}=.01\right]$. The interactions between presentation rate and type of test; presentation rate and emphasis condition; and presentation rate, type of test, and emphasis condition did not approach significance.

Slowing presentation rate improved recognition performance on the final recognition test for both item and

\section{ITEM RECOGNITION ASSOCIATIVE RECOGNITION}

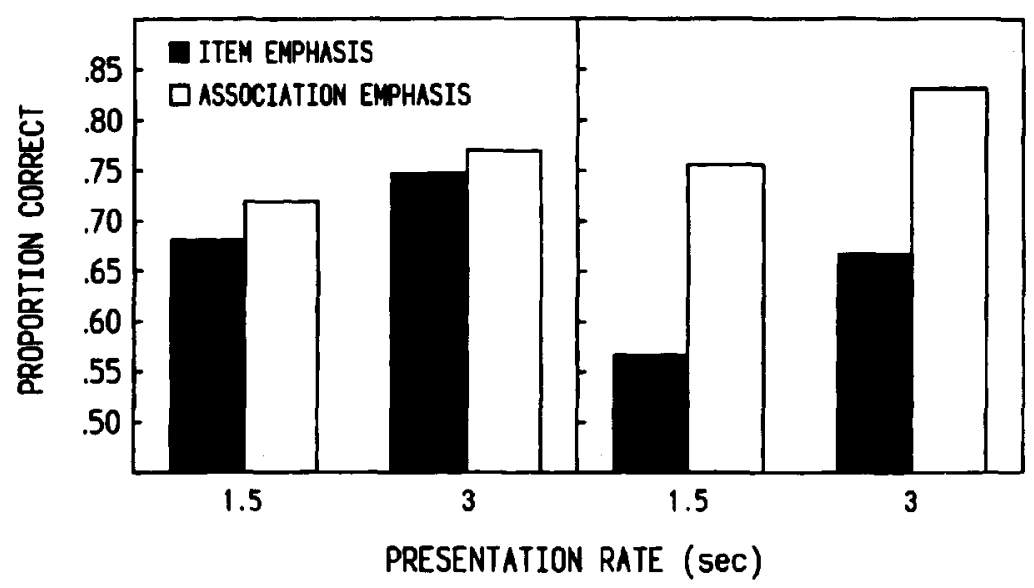

Figure 2. Mean proportion correct for item and associative recognition for each rate of presentation and emphasis condition of Experiment 2. 
associative recognition. The effects of presentation rate, however, did not change the pattern of results found in Experiment 1. Associative recognition performance was significantly greater in the association emphasis condition than in the item emphasis condition at both the 1.5 sec presentation rate $[t(38)=4.04]$ and the 3 -sec rate $[t(38)=3.91]$. In contrast, item recognition performance did not differ statistically between the item emphasis and the association emphasis groups at either the $1.5-\mathrm{sec}$ presentation rate $[t(38)=0.98]$ or the $3-\sec$ rate $[t(38)=$ $0.64]$. Thus, when item information was emphasized, less associative information was encoded. When associative information was emphasized, however, the gain in accuracy for associative recognition was not made at the expense of item information. Emphasizing associative information did not diminish recognition memory for item information.

Experiment 3 was designed to replicate the results of Experiment 2 across a wider range of presentation rates. Response time was also measured in Experiment 3 in order to determine whether the latencies of item and associative recognition decisions would be comparable in both emphasis conditions.

\section{EXPERIMENT 3}

\section{Method}

Participants. Forty students participated for course credit. Twenty students were assigned to each emphasis condition.

Stimuli. All words were selected from a 1,000-word version of the Toronto word pool (Friendly, Franklin, Hoffman, \& Rubin, 1982), a collection of common two-syllable nouns and non-nouns (adjectives, verbs, and adverbs; e.g., ugly, discuss, greatly).

Procedure. There were nine different study-test trials in each session. Study pairs were presented at a 1-, 2-, or 4-sec rate. Three study lists were presented at each rate, and the order of lists within each session was random. The final recognition test consisted of 6 item and 6 associative forced-choice comparisons from each study list for a total of 108 test presentations. Participants were instructed to respond both as accurately and as quickly as possible, but the emphasis was placed on accuracy. Response latency was recorded from the onset of the test probe to the keypress for both immediate and final tests. In all other respects, the procedure of Experiment 3 was identical to that of Experiment 2.

\section{Results and Discussion}

The mean proportions of items correctly identified on the immediate tests at presentation rates of 1,2 , and $4 \mathrm{sec}$ were $.76, .82$, and .90 , respectively. The corresponding

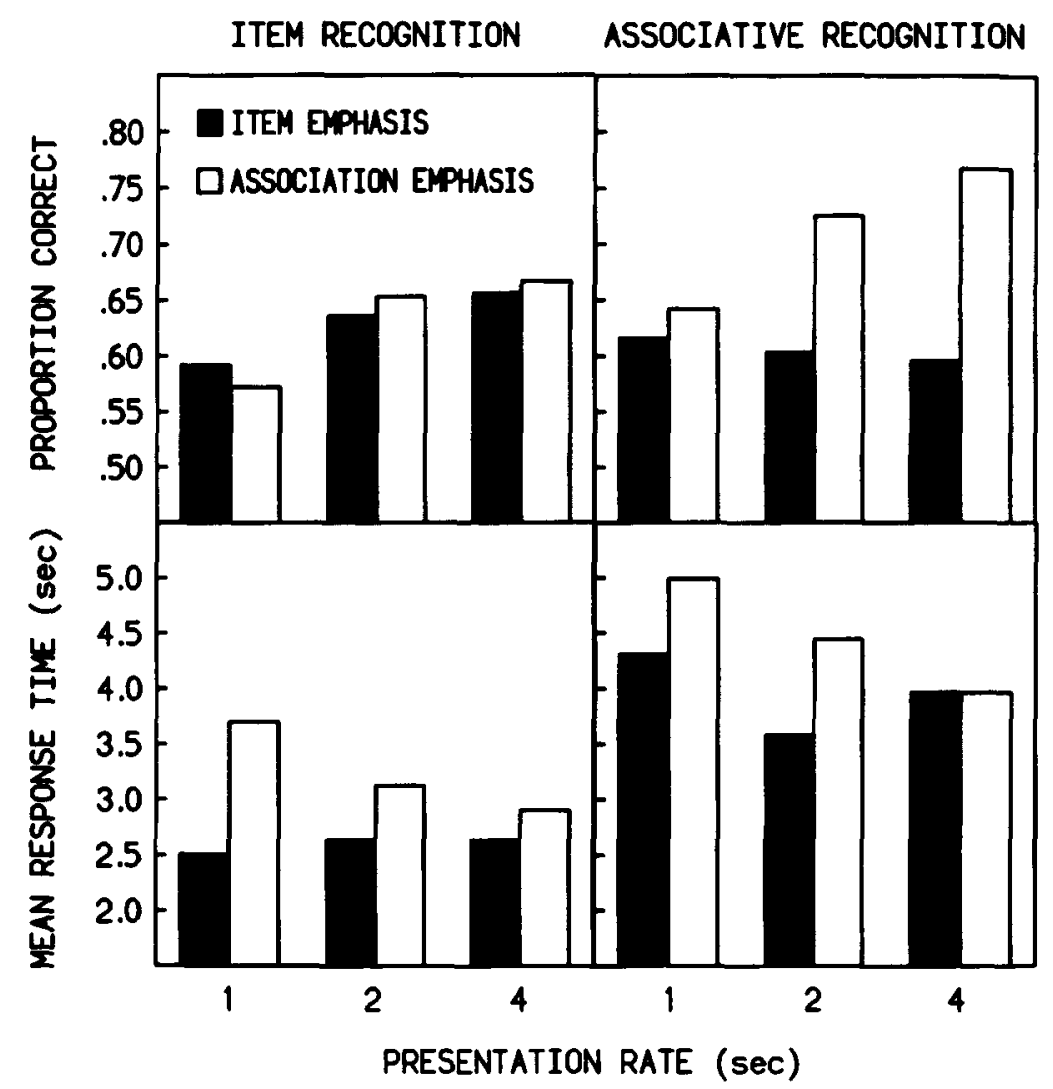

Figure 3. Mean proportion correct (top) and mean response time for hits (bottom) for item and associative recognition for each presentation rate and emphasis condition of Experiment 3. 
means for associative recognition were $.72, .81$, and .84 . The main effect of type of test was not significant $[F(1,38)$ $\left.=1.44, M S_{\mathrm{e}}=.04\right]$. The increase in recognition performance as a function of presentation rate was highly reliable $\left[F(2,76)=16.18, M S_{\mathrm{e}}=.01\right]$. Both item and associative recognition benefited from slower presentation rates to a similar extent; the interaction between type of test and presentation rate did not approach significance $[F(2,16)<1]$.

The mean proportions of items and associations correctly recognized on the final test for each presentation rate in each emphasis condition are shown in the top panels of Figure 3 . The main effects of emphasis condition $\left[F(1,38)=3.69, M S_{\mathrm{e}}=.05\right]$ and type of test $[F(1,38)=$ $\left.2.49, M S_{\mathrm{e}}=.02\right]$ were not reliable. The main effect of presentation rate $\left[F(2,76)=7.28, M S_{\mathrm{e}}=.01\right]$ and the interactions between emphasis and presentation rate $\left[F(2,76)=3.29, M S_{\mathrm{e}}=.01\right]$ and emphasis and type of test $\left[F(1,38)=8.27, M S_{\mathrm{e}}=.02\right]$ were significant.

The results of the final recognition test replicate the principal findings of Experiment 2 . The accuracy of associative recognition was greater when associative information was emphasized than when item information was emphasized. This difference was not reliable at the 1 -sec presentation rate $[t(38)=0.63]$, but was significant at both the 2 -sec rate $[t(38)=2.50]$ and the 4 -sec rate $[t(38)=3.92]$. The accuracy of item recognition was comparable, and did not differ statistically, between the item and association emphasis groups at each presentation rate.

Mean latencies were calculated for correct responses based on subject means. For the immediate tests, mean correct latencies for item recognition at the 1-, 2-, and 4 -sec presentation rates were $1.99,1.85$, and $1.91 \mathrm{sec}$, respectively. The corresponding means for associative recognition were $4.14,3.41$, and $3.46 \mathrm{sec}$. Item recognition responses were faster than associative recognition responses $\left[F(1,38)=26.58, M S_{\mathrm{e}}=35,067.8\right]$. The main effect of presentation rate was not reliable $[F(2,76)=$ $\left.2.50, M S_{\mathrm{e}}=827.9\right]$, and the interaction between type of test and presentation rate did not approach significance.

The mean correct response latencies for item and associative recognition at each presentation rate for each emphasis condition for the final recognition test are shown in the lower panels of Figure 3. The main effects of type of test $\left[F(1,38)=56.28, M S_{\mathrm{e}}=1,782.1\right]$ and presentation rate $\left[F(2,76)=7.84, M S_{\mathrm{e}}=764.4\right]$ were reliable. The main effect of type of information emphasized did not approach significance $\left[F(1,38)=1.27, M S_{\mathrm{e}}=16,030.3\right]$. The only reliable interaction was between type of information emphasized and presentation rate $[F(2,76)=$ $\left.4.40, M S_{\mathrm{e}}=764.4\right]$. This interaction reflects the fact that response latency decreased with presentation rate when associative information was emphasized but response latency did not vary systematically with presentation rate when item information was emphasized.

Response latency was measured in Experiment 3 in order to assess, at least indirectly, the possibility that subjects used different recognition decision strategies, de- pending whether item or associative information had been emphasized at study. The pattern of response latencies is equivocal in this regard, as no consistent relationship between emphasis and latency was found. Overall mean response latencies were, though, relatively slow, particularly on the final recognition test. The question as to whether encoding emphasis influences response latency is considered again in Experiment 5.

In Experiment 4, word concreteness was manipulated. Half of the study lists were composed of pairs of words that had high concreteness (HC) values, and half were composed of pairs of words that had low concreteness (LC) values. Recognition performance for both item and associative recognition is greater for $\mathrm{HC}$ words than for LC words (e.g., Hockley, 1994). It was expected that the advantage for $\mathrm{HC}$ word pairs over LC word pairs for associative recognition would be greater when associative information was emphasized at study than when item information was emphasized. The question of central interest was whether the advantage of $\mathrm{HC}$ words over LC words for item recognition would be comparable when associative information was emphasized as when item information was emphasized. If there is a tradeoff between item and associative information in the associative emphasis condition, the tradeoff should be more evident for LC words because they are more difficult to associate than $\mathrm{HC}$ words.

A confidence judgment response procedure was also used in Experiment 4 in order to compare participants' degree of confidence in their item and associative recognition decisions when item or associative information was emphasized.

\section{EXPERIMENT 4}

\section{Method}

Participants. Thirty-eight students, 19 in each emphasis condition, participated for course credit.

Stimuli. The word pool consisted of $240 \mathrm{HC}$ nouns and $240 \mathrm{LC}$ nouns selected from Paivio et al. (1968). According to the Paivio et al. norms, the $\mathrm{HC}$ nouns had a mean concreteness value of 6.71 , a mean imagery value of 6.27 , and a mean meaningfulness value of 6.67. The corresponding means for LC nouns were 2.46, 3.32, and 5.01.

Procedure. There were six different study-test trials in each session. Three study lists were composed of $\mathrm{HC}$ word pairs, and three lists were composed of LC word pairs. The order of lists within each session was determined randomly. All study lists were presented at a $3-\mathrm{sec}$ per pair rate.

Participants indicated their recognition and confidence responses by using the keys R, T, Y, U, I, and $\mathrm{O}$, which were labeled sure, maybe, guess, guess, maybe, and sure, respectively. Subjects used the left three response keys to indicate that the left item or pair test probe was old, and the right three keys to indicate that the test probe on the right was old. Participants responded at their own pace. In all other respects, the procedure of Experiment 4 was the same as in Experiment 1.

\section{Results and Discussion}

Accuracy and confidence judgments were analyzed separately. Accuracy was measured by collapsing over confidence judgments. Mean confidence ratings for cor- 


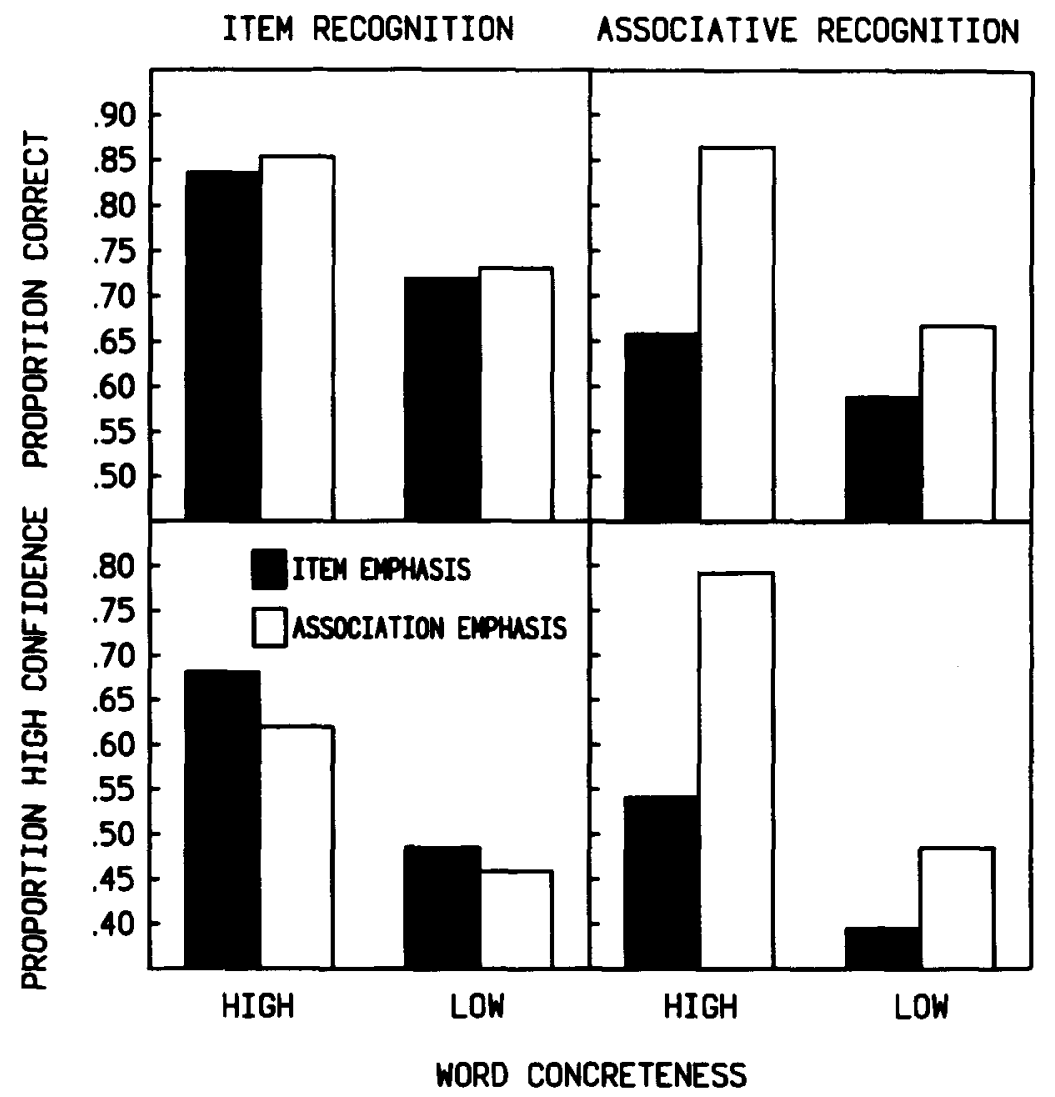

Figure 4. Mean proportion correct (top) and mean proportion of correct high confident responses (bottom) for item and associative recognition for words of high and low concreteness in each emphasis condition of Experiment 4.

rect responses were calculated by scoring "sure" responses as 3, "maybe" responses as 2 , and "guess" responses as 1 . Analyses of mean correct confidence ratings and the proportion of correct high-confident ("sure") responses yielded similar results. Consequently, only the analysis of proportion of correct high-confident responses are reported.

For the immediate tests, the proportions of correct responses and correct high-confident responses for item recognition were, respectively, .88 and .75 for $\mathrm{HC}$ words and .83 and .64 for LC words. The corresponding means for associative recognition were .91 and .85 for $\mathrm{HC}$ word pairs and .79 and .59 for LC word pairs. An ANOVA based on the proportion of correct responses revealed only a significant main effect of word concreteness $\left[F(1,36)=17.67, M S_{\mathrm{e}}=\right.$ $.007]$, as did the analysis of proportion of correct high confident responses $\left[F(1,36)=57.69, M S_{\mathrm{e}}=.093\right]$. Accuracy and confidence was greater for $\mathrm{HC}$ words than $\mathrm{LC}$ words for both item and associative recognition.

The proportions of correct item and associative recognition responses for $\mathrm{HC}$ and $\mathrm{LC}$ words in each emphasis condition for the final recognition test are presented in the top panels of Figure 4. The corresponding mean proportions of correct high-confident responses are shown in the lower panels of Figure 4.
In the analysis of the proportion of correct responses, the main effects of emphasis instructions $[F(1,36)=$ $\left.7.93, M S_{\mathrm{e}}=.03\right]$, word concreteness $[F(1,36)=76.56$, $\left.M S_{\mathrm{e}}=.01\right]$, and type of test $\left[F(1,36)=22.00, M S_{\mathrm{e}}=\right.$ $.01]$ were all reliable. The main effects were qualified by interactions between emphasis and word concreteness $\left[F(1,36)=5.36, M S_{\mathrm{e}}=.01\right]$, emphasis and type of test $\left[F(1,36)=11.05, M S_{\mathrm{e}}=.01\right]$, and emphasis, concreteness, and type of test $\left[F(1,36)=4.29, M S_{\mathrm{e}}=.01\right]$.

This pattern of results shows that associative recognition performance was greater when associative information was emphasized than when item information was emphasized. This difference was reliable for $\mathrm{HC}$ word pairs $[t(36)=4.39]$ and approached significance for $\mathrm{LC}$ word pairs $[t(36)=1.84, p=.074]$. Associative recognition was also more accurate for $\mathrm{HC}$ word pairs than for LC word pairs, and this effect was greater when associative information was emphasized. Item recognition was also more accurate for $\mathrm{HC}$ words than for $\mathrm{LC}$ words. This effect, however, was not influenced by encoding emphasis. Item recognition performance did not differ reliably between emphasis conditions for either $\mathrm{HC}$ words $[t(36)=.054]$ or $\mathrm{LC}$ words $[t(36)=0.34]$.

In the analysis of proportion of correct high-confident responses on the final recognition test, the main effect of 
word concreteness was significant $[F(1,36)=117.3$, $\left.M S_{\mathrm{e}}=.01\right]$. The main effects of emphasis intructions $\left[F(1,36)=1.57, M S_{\mathrm{e}}=.10\right]$ and type of test $[F(1,36)<$ 1] were not reliable, but the interactions between emphasis and type of test $\left[F(1,36)=19.24, M S_{\mathrm{e}}=.02\right]$ and between word concreteness, emphasis, and type of test $\left[F(1,36)=5.72, M S_{\mathrm{e}}=.02\right]$ were significant. The proportion of correct high-confident responses was greater for $\mathrm{HC}$ words than for $\mathrm{LC}$ words for both item and associative recognition. The proportion of high-confident correct responses for associative recognition was greater when associative information was emphasized than when item information was emphasized. This difference was significant for $\mathrm{HC}$ words $[t(36)=3.83]$ but was not reliable for $\mathrm{LC}$ words $[t(36)=1.78, p=.084]$. The proportion of high-confident correct responses for item recognition did not differ statistically between emphasis conditions, either for $\mathrm{HC}$ words $[t(36)=0.90]$ or for LC words $[t(36)=0.40]$.

The results of Experiment 4 replicate and extend the previous findings. Associative recognition was more accurate and more confident, and the effect of word concreteness was greater, when associative information was emphasized than when item information was emphasized. The accuracy and confidence of item recognition, and the effects of word concreteness on item recognition, were not reliably influenced by encoding emphasis.

Word concreteness benefits both item and associative information. In Experiment 5, natural language word frequency was manipulated. Word frequency has been shown to have a differential effect on item and associative recognition in that there is a low-frequency advantage for item recognition and either a high-frequency advantage (Clark, 1992; Clark \& Burchett, 1994; Clark \& Shiffrin, 1992) or no effect of word frequency (Hockley, 1994) for associative recognition.

High-frequency (HF) words may be easier to associate than low-frequency (LF) words, because HF words have more senses or semantic interpretations (Reder, Anderson \& Bjork, 1974). If this is the case, it should be more likely to find an encoding tradeoff for LF words because it may be more difficult to form associations between them.

Alternatively, Begg and Azzarello (1988) have argued that

Although relational encoding does not cause items to be encoded less distinctively, the demand to relate items may bias encoding so that the items are specific to their contexts. For example, the demand to imagine mother interacting with railroad may cause a different encoding of mother from when mother appears alone as a cue. (p. 328)

Because HF words have more possible semantic interpretations than LF words have, HF words should suffer from context effects more than should LF words. Thus, if encoding variability is a factor in the recognition of single items encoded as a member of a pair as opposed to items encoded individually, the recognition of HF words should suffer in the associative emphasis condi- tion to a greater extent than should that of LF words. One purpose, therefore, of Experiment 5 was to determine whether the effects of word frequency on item recognition vary with encoding emphasis.

The word frequency manipulation of Experiment 5 also afforded an opportunity to determine whether encoding emphasis influences the mirror effect (Glanzer \& Adams, 1985) for item recognition. With respect to word frequency, the mirror effect refers to the finding that LF words are more accurately recognized as old when old and more accurately recognized as new when new. That is, performance on new items mirrors performance on old items (see Glanzer \& Adams, 1990; Glanzer, Adams, Iverson, \& Kim, 1993; Hintzman, 1994; Hockley, 1994, for recent discussions of the mirror effect).

Another purpose of Experiment 5 was to further compare response latency for item and associative recognition decisions in each encoding emphasis condition. In Experiment 3, correct response latencies were relatively slow. This may have been partly the result of the forcedchoice procedure, which requires more time for participants to process two test probes. In Experiment 5, a yes-no recognition test procedure was used.

\section{EXPERIMENT 5}

\section{Method}

Participants. Forty students, 20 in each emphasis condition, participated for payment.

Stimuli. All words were randomly selected from Glanzer and Adams's (1990) pool of 248 HF words (mean frequency of 177.3 per million, based on the norms of Kučera \& Francis, 1967) and 248 LF words (mean Kučera-Francis frequency of 11.2).

Procedure. There were six study-test trials in each session. Study lists were constructed in the same manner as in Experiment 4 . Three study lists were composed of HF word pairs and three lists were composed of LF word pairs. The order of lists within each session was random. Study lists were presented at a rate of $3 \mathrm{sec}$ per pair.

The immediate test lists consisted of 12 presentations. In the item emphasis condition, there were 6 single old items and 6 new items from the same frequency class. In the association emphasis

Table 1

Mean Proportion of "Yes" Responses to New and Old Test Probes for High- and Low-Frequency (HF, LF) Words for the Item and Associative Recognition Test Conditions of Experiment 5

\begin{tabular}{|c|c|c|c|c|}
\hline \multirow[b]{3}{*}{ Test } & \multicolumn{4}{|c|}{ Test Probe } \\
\hline & \multicolumn{2}{|c|}{ New } & \multicolumn{2}{|c|}{ Old } \\
\hline & LF & $\mathrm{HF}$ & $\mathrm{HF}$ & $\mathrm{LF}$ \\
\hline \multicolumn{5}{|l|}{ Immediate Test } \\
\hline Item recognition & .122 & .125 & .731 & .806 \\
\hline Associative recognition & .114 & .114 & .850 & .861 \\
\hline \multicolumn{5}{|l|}{ Final Test } \\
\hline \multicolumn{5}{|l|}{ Item recognition } \\
\hline Item emphasis & .206 & .347 & .681 & .694 \\
\hline Associative emphasis & .144 & .289 & .633 & .664 \\
\hline \multicolumn{5}{|l|}{ Associative recognition } \\
\hline Item emphasis & .386 & .319 & .597 & .656 \\
\hline Associative emphasis & .108 & .092 & .733 & .817 \\
\hline
\end{tabular}


condition, there were 6 intact test pairs and 6 rearranged pairs. The order of test presentations was random.

The final recognition test list consisted of 6 intact pairs, 6 rearranged pairs, and 6 single old items from each study list and 36 new single words ( $18 \mathrm{HF}$ and $18 \mathrm{LF}$ ) for a total of 144 test presentations. The order of the tests was random.

The test list was subject paced. Participants indicated whether the probe item or the probe pair was new or old by pressing the " $Z$ " key or the "/" key, respectively. Participants were encouraged to respond both as accurately and as quickly as possible, but accuracy was emphasized over speed.

\section{Results and Discussion}

The mean proportion of "yes" responses to new and old test probes (i.e., false alarms and hits) for both item and associative recognition on both the immediate and final tests are presented in Table 1. The means are arranged in each row of Table 1 such that the mirror effect is evidenced by an increase in the means from left to right.

Neither item nor associative recognition showed a mirror effect on the immediate tests. Item recognition was greater for HF than for LF words, but this difference was limited to hit rates. The mirror effect can, however, be seen in the pattern of results for item recognition on the final test. Hit rates were greater and false alarm rates were lower for LF words than for HF words. Associative recognition did not exhibit a mirror effect. Hockley (1994) also found a mirror effect for item recognition but no mirror effect for associative recognition when word frequency was manipulated.

It is interesting to note in passing that the proportion of "yes" responses for item recognition on the final test was consistently higher in the item emphasis condition than in the associative emphasis condition. That is, both the false alarm rates and the hit rates for item recognition were higher in the item emphasis condition. In terms of signal detection theory, this pattern suggests that encoding emphasis may influence the recognition decision criterion. Participants in the association emphasis condition adopted a more conservative item recognition decision criterion than did participants in the item emphasis condition.

In order to compare the effects of encoding emphasis on memory for item and associative information on the final recognition test, mean $d^{\prime}$ values (based on subject mean hit and false alarm rates) were calculated separately for HF and LF stimuli. Mean $d^{\prime}$ values for each condition are presented in the top panels of Figure 5. Mean response times for hits (correct responses to old items and intact pairs) were also calculated and are presented in the bottom panels of Figure 5.

In the analysis of final recognition test performance based on $d^{\prime}$, the main effects of emphasis condition

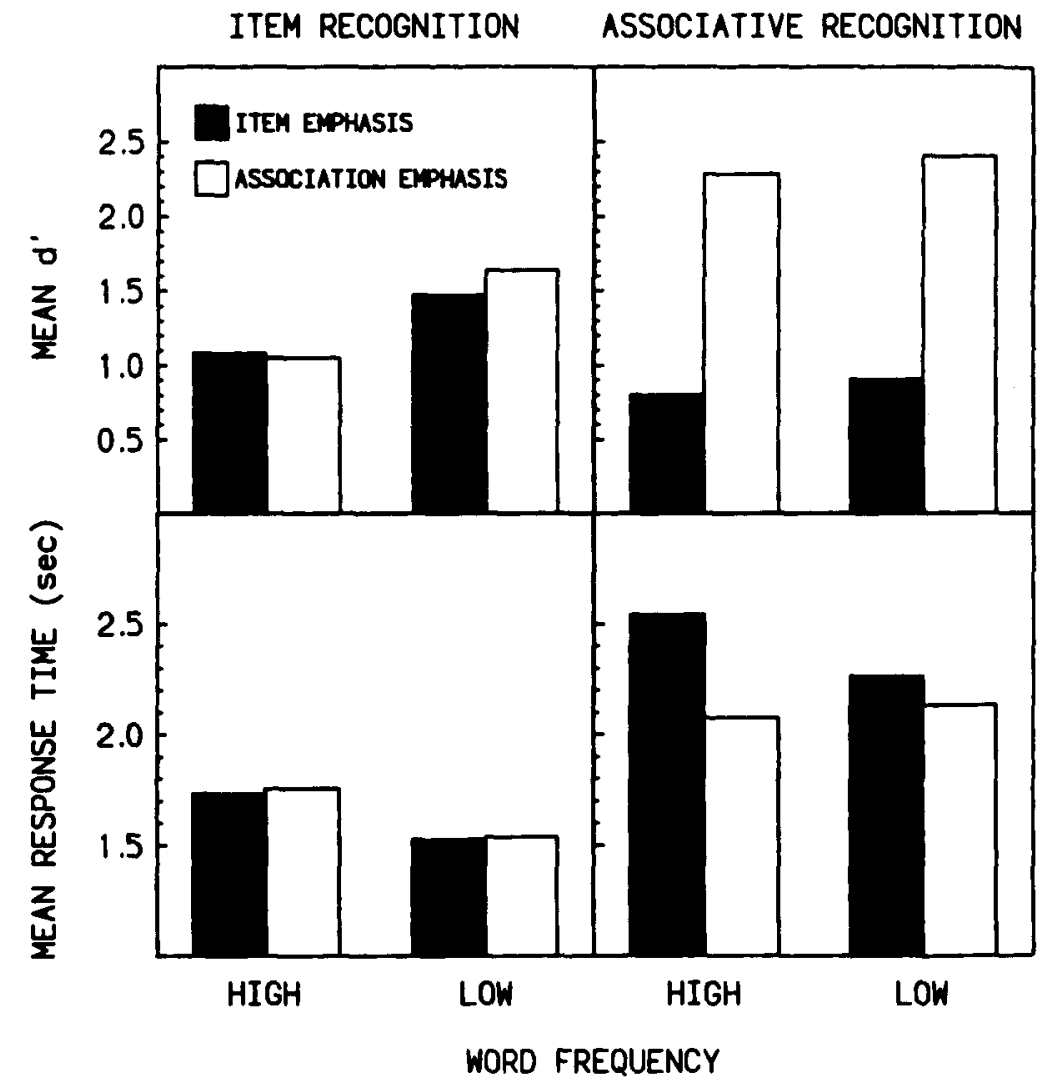

Figure 5. Mean $d^{\prime}$ (top) and mean response time for hits (bottom) for item and associative recognition for high- and low-frequency words in each emphasis condition of Experiment 5. 
$\left[F(1,38)=15.23, M S_{\mathrm{e}}=1.61\right]$, type of test $[F(1,38)=$ $\left.4.47, M S_{\mathrm{e}}=0.74\right]$, and word frequency $[F(1,38)=$ $\left.27.56, M S_{\mathrm{e}}=0.74\right]$ were all reliable. The main effects were qualified by two significant interactions-emphasis condition $\times$ type of test $\left[F(1,38)=27.56, M S_{\mathrm{e}}=\right.$ $0.74]$, and type of test $\times$ word frequency $[F(1,38)=$ $\left.4.27, M S_{\mathrm{e}}=0.34\right]$. Associative recognition was not influenced by word frequency. Associative recognition was greater in the association emphasis condition than in the item emphasis condition. This difference was reliable for both $\mathrm{HF}$ words $[t(38)=5.25]$ and LF words $[t(38)=$ 4.53]. Item recognition showed the opposite pattern of results. Item recognition was, as typically found, greater for $\mathrm{LF}$ words than for HF words. This difference was reliable in both the item emphasis condition $[t(19)=1.78]$ and the association emphasis condition $[t(19)=2.65]$. Encoding emphasis did not significantly affect item recognition performance. This was true for both $\mathrm{HF}$ words $[t(38)=0.12]$ and LF words $[t(38)=0.81]$.

The analysis of mean response latency for hits on the final recognition test showed that the main effects of type of test $\left[F(1,38)=64.2, M S_{\mathrm{e}}=236.2\right]$ and word frequency $\left[F(1,38)=7.57, M S_{\mathrm{e}}=139.7\right]$ were significant. The main effect of encoding emphasis was not significant $[F(1,38)<1]$, but the interaction between emphasis and type of test $\left[F(1,38)=4.22, M S_{\mathrm{e}}=236.2\right]$ was reliable. Not surprisingly, response latency was slower for associative recognition than for item recognition. Associative recognition was faster when associative information was emphasized than when item information was emphasized. This difference was significant for $\mathrm{HF}$ word pairs $[t(38)=2.06]$ but was not reliable for LF word pairs $[t(38)=0.62]$. Response latency for item recognition mirrored the pattern of results for mean $d^{\prime}$. LF words were responded to faster than HF words. This effect, however, was not statistically reliable in either the item emphasis condition $[t(19)=0.83]$ or the association emphasis condition $[t(19)=1.44]$. Encoding emphasis did not significantly affect response latency.

The results of Experiment 5 replicated the principal finding of the previous experiments-recognition memory for associations was less accurate in the item emphasis condition than in the associative emphasis condition, but recognition memory for item information was statistically equivalent in the two emphasis conditions. Experiment 5 also showed that the typical LF advantage in item recognition was not attenuated in the association emphasis condition. Finally, the analysis of response latency in Experiment 5 showed that mean response time for item recognition was virtually identical in the two encoding emphasis conditions, further indicating that item recognition is not in any measurable way diminished when associative information is emphasized.

The results of Experiment 5, therefore, do not provide any support for an encoding tradeoff between item and associative information when associative information is emphasized. The results also do not indicate that item recognition in the associative emphasis condition was influenced by encoding variability, since the levels of item recognition for both $\mathrm{HF}$ and $\mathrm{LF}$ words were equivalent in the item and associative emphasis conditions.

In all of the experiments reported thus far, participants in the association emphasis condition were encouraged to either form interactive images of the two words of each pair, or generate a sentence that included both words. These instructions were used because previous research has shown that these two associative strategies are the most effective. For example, Bower and Winzenz (1970) compared the effectiveness of four associative strategies and found interactive imagery to be the best, followed closely by sentence generation, followed by reading a sentence that included the to-be-remembered word pair, followed by rote repetition, which was the least effective strategy. Dempster and Rowher (1974) made a similar comparison with children and found comparable results. These studies demonstrate that memory for associations varies, depending on the associative strategy that is used. Does memory for item information also vary depending on the associative strategy?

Experiment 6 was designed to determine the extent to which memory for both item and associative information varies as a function of the nature of the associative strategy that is used to relate random word pairs. Subjects were instructed to always form interactive images of the word pairs, or to generate sentences that included both words, or to rehearse the word pair by using rote repetition. Memory for both item and associative information was evaluated in a final unexpected recognition test.

\section{EXPERIMENT 6}

\section{Method}

Participants. Sixty undergraduate students, 20 in each instruction condition, participated for payment.

Stimuli. The word pool consisted of the 480 concrete nouns that were used in Experiments 1 and 2.

Procedure. The procedure was the same as for the association emphasis condition of Experiment 1, with the following exceptions. One group of participants was instructed to always associate



Figure 6. Mean proportion correct for item and associative recognition ( $r n$ ) for the three association instruction conditions of Experiment 6. 
the word pairs by forming an interactive image of the two words. A second group was instructed to always associate the pairs by generating a sentence that included both words. A third group was instructed to silently rehearse the word pair in a rote fashion. The importance of only performing the assigned strategy was emphasized. Study lists were presented at a rate of $3 \mathrm{sec}$ per pair. At the end of the session, participants were asked how well they were able to follow the assigned associative strategy.

\section{Results and Discussion}

The mean proportions of correct responses on the immediate associative recognition tests were $.96, .96$, and .78 , for the imagery, sentence, and rote instruction conditions, respectively. The mean proportions of correct responses for both item and associative recognition on the final test are shown in Figure 6 . On both the immediate and final tests, imagery and sentence generation instructions led to higher performance than did rote repetition instructions. A 2 (item vs. associative tests) $\times 3$ (associative instructions) ANOVA based on final test performance revealed that the main effects of instruction $[F(2,57)=$ $\left.33.58, M S_{\mathrm{e}}=.02\right]$ and type of test $[F(1,57)=16.30$, $\left.M S_{\mathrm{e}}=.07\right]$ and their interaction $\left[F(2,57)=3.23, M S_{\mathrm{e}}=\right.$ $.01, p=.047]$ were reliable. Both item and associative recognition were greater in the imagery and sentence generation conditions than in the rote repetition condition.

The results of Experiment 6 show that imagery and sentence generation lead to better associative memory than did rote repetition replicating the findings of Bower and Winzenz (1970) and Dempster and Rowher (1974). More importantly, when associative information was emphasized, the nature of the associative strategy affected subsequent associative and item recognition in the same manner. That is, strategies that benefited associative recognition also benefited item recognition, and the less beneficial strategy for associative recognition was also less effective for item recognition. The results of Experiment 6 do not provide any evidence of an encoding tradeoff between item and associative information when associative information is emphasized; rather, the results indicate that item and associative information are encoded together when associative information is emphasized.

Participants in each instruction condition were asked whether they were able to follow the assigned associative instructions all, most, or some of the times. All participants in the rote repetition condition reported that they always followed the instructions. Eighteen subjects in the imagery condition and 17 subjects in the sentence generation condition reported that they followed the instructions all or most of the time. In addition, participants in the sentence generation condition were asked if they also "saw an image of the two words" when they were constructing a sentence: 3 reported "sometimes," 5 reported "most times," and 12 reported "always." The fact that the participants in the sentence condition also spontaneously generated images is likely the reason why the imagery and sentence generation strategies resulted in such similar levels of item and associative recognition performance.

\section{GENERAL DISCUSSION}

This study was designed to determine whether there is a tradeoff between the encoding of item and associative information for random word pairs by evaluating the effect of emphasizing one type of information on subsequent memory for the other type of information. When item information was emphasized, recognition memory for associative information was relatively poor. When associative information was emphasized, recognition memory for associations greatly improved. This pattern of results demonstrates that participants followed the emphasis instructions. It is, therefore, reasonable to assume that participants spent more time encoding item information rather than associative information in the item emphasis condition, and that the time devoted to encoding associative information was greater in the association emphasis condition than in the item emphasis condition.

The fact that memory for associations was relatively poor compared with memory for item information in the item emphasis condition indicates that participants can encode item information and, to a considerable extent, ignore associative information. In contrast, when participants emphasized associative information, memory for associations greatly improved, but memory for item information did not suffer. Thus, the increased encoding of associative information was not made at the expense of memory for item information.

In Experiments 2 and 3, presentation rate was varied. Both item and associative recognition performance increased with increases in presentation rate on the immediate tests, indicating that more information was encoded with greater study time. In both experiments, the interaction between presentation rate and type of test was not significant. Although there is a suggestion in Experiment 2 that the increase with presentation rate was greater for associative recognition, in Experiment 3 the absolute increase in accuracy from 1 to $4 \mathrm{sec}$ was identical for item and associative recognition. This result represents a failure to replicate the greater increase in associative recognition with presentation rate reported by Clark and Shiffrin (1992). The present results, however, do not permit a more fine-grained examination of the relative encoding rates of item and associative information as a function of presentation rate.

On the final recognition tests of Experiments 2 and 3, associative recognition accuracy increased with presentation rate when associative information was emphasized, and item recognition accuracy increased as a function of presentation rate in both emphasis conditions. Moreover, there was no evidence of a tradeoff between item and associative information for the association emphasis group at either fast or slow presentation rates. These results indicate that the failure to find a tradeoff in the associative emphasis condition was not a result of participants' having either insufficient time to emphasize the encoding of associative information, or sufficient time to emphasize both types of information. 
It is also highly unlikely that the failure to find an encoding tradeoff in the association emphasis condition was due to the use of stimulus materials that were "too easy" to associate. In Experiments 1 and 2, the word pool consisted of concrete nouns that were relatively easy to associate. Thus one might argue that, for these materials, participants in the association emphasis condition could encode both item and associative information in the time available. However, no evidence for an encoding tradeoff was found in Experiment 3, where the word pool consisted of both nouns and non-nouns (adjectives, verbs, and adverbs). In Experiment 4, word concreteness was directly manipulated. Both item and associative recognition were more accurate for $\mathrm{HC}$ words than for $\mathrm{LC}$ words. Given that LC words are more difficult to associate, it should be more likely to find an encoding tradeoff for $\mathrm{LC}$ words than for $\mathrm{HC}$ words. However, there was no evidence of a tradeoff in the association emphasis group when the stimuli were either $\mathrm{HC}$ or LC words. Finally, in Experiment 5, word frequency was varied. On the final recognition test, the typical LF advantage for item recognition was obtained and this advantage was not attenuated in the association emphasis condition. In contrast, word frequency did not significantly affect associative recognition performance.

It is possible to consider that participants in the association emphasis condition might try to augment item recognition decisions with an attempt to recall the associative information that was encoded with the item. Such a strategy could improve the accuracy of item recognition. Participants in the item emphasis condition would not, presumably, attempt such a strategy very often, because they did not encode sufficient associative information for this strategy to be very useful. However, the possibility that participants in the associative emphasis condition used a different strategy for item recognition from that used by participants in the item emphasis condition seems unlikely, because both the pattern of response latencies in Experiments 3 and 5 and the pattern of confidence judgments in Experiment 4 do not suggest any substantial differences in the processes underlying item recognition in the two emphasis conditions.

Finally, the results of Experiment 6 showed that when associative information was emphasized, the nature of the associative encoding strategy had a similar effect on item and associative memory-imagery and sentence generation instructions benefited both item and association recognition, whereas rote repetition led to a decrease in both item and associative recognition. This finding indicates that item and associative information do not trade off at encoding, but rather are encoded together when associative information is emphasized.

The failure to find an encoding tradeoff when associative information is emphasized provides strong evidence against the limited capacity assumption of current versions of TODAM (e.g., Murdock, 1992). One could, of course, drop this assumption from TODAM. This would necessitate a reinterpretation of the attentional or weighting parameters for item and associative information that are an integral feature of TODAM.

Murdock (1993) has recently presented a modified and expanded version of TODAM (TODAM2) that is designed to provide a unified account of item, associative, and serial-order information. TODAM2 extends the chunking model of Murdock (1992), which is based on n-grams (multiple convolutions of item vectors), to include rn-grams (reduced n-grams), labels (names or retrieval cues for chunks), and "lebals" (the involution of a label, which provides a second, independent retrieval cue). Briefly, chunks, or n-grams and rn-grams, are stored, and labels and lebals, respectively, are used to retrieve them.

An important feature of TODAM2 is that the representation of contextual information is made explicit. Individual items are encoded in context. In addition, item information is also embedded in the representation of associative information so there are two bases for item recognition. Thus, TODAM 2 consists of four components: contextual information, item information, context-toitem associative information, and item-to-item associative information. It is also assumed that contextual information contributes to item recognition but does not play a role in associative recognition. Murdock (1995) has recently argued that such a version of TODAM2 can fit the present results as exemplified in Figure 1.

The search of associative memory, or SAM, model (Gillund \& Shiffrin, 1984; Raaijmakers \& Shiffrin, 1981) can also provide an account of the present findings. In SAM, item and associative information are encoded separately, and as in TODAM, the strengths or weights of the two types of information can differ. At test, however, item and associative information are assumed to be retrieved together. That is, both item information (self-strength) and associative information (interitem strength) contribute to the overall familiarity of both item and associative test probes. Thus, although it is possible to assume that item and associative information can trade off at encoding in SAM, this tradeoff need not result in differences in recognition performance, because item and associative information are combined at retrieval.

It should be noted, though, that the present tests of an encoding tradeoff between item and associative information do not provide a critical or definitive test of TODAM2 or SAM. Although the present failure to find evidence for an encoding tradeoff between item and associative information when associative information is emphasized is consistent with the general assumptions of these models, it is quite likely that these models could also account for an encoding tradeoff by assuming that different amounts of contextual information are encoded when subjects emphasize item or associative information. For example, in SAM, higher values of the context parameter for items processed individually than for items processed as a member of a pair would produce higher familiarity values for the items processed individually. 
Although the present findings provide a measure of support for the SAM model, the encoding-independence/ retrieval-dependence assumptions of this model present problems in accounting for other findings that demonstrate differences between item and associative information. As noted in the introduction, item and associative recognition have been found to have different temporal dynamics (Gronlund \& Ratcliff, 1989) and different rates of forgetting (Hockley, 1991, 1992), and differ with respect to the effects of natural language word frequency (e.g., Clark, 1992; Hockley, 1994; and Experiment 5 of the present study).

The present study demonstrates that when item information is emphasized, subjects can effectively encode item information and largely ignore associative information. In contrast, when associative information is emphasized, both item and associative information are encoded and the additional processing of associative information does not diminish subsequent item recognition performance. That is, there is no tradeoff between item and associative information that is reflected indion performance. This result indicates either that item and associative information are processed and encoded together, as is assumed in TODAM2, or that there may be a tradeoff at encoding but associative information augments item information at retrieval, as is assumed in the SAM model. However, given the differences between item and associative recognition noted above, it would seem more likely that models that assume encoding dependence and retrieval independence are in a better position to provide a more parsimonious account of recognition memory for item and associative information.

\section{REFERENCES}

ANDERson, J. R., \& Bower, G. H. (1972). Recognition and retrieval processes in free recall. Psychological Review, 79, 97-123.

BaIN, J. D., \& HumPHREYS, M. S. (1988). Relational context: Independent cues, meanings, or configurations? In G. M. Davies \& D. M. Thompson (Eds.), Memory in context: Context in memory (pp. 97-137). London: Wiley.

Balota, D. A., \& Neely, J. H. (1980). Test-expectancy and wordfrequency effects in recall and recognition. Journal of Experimental Psychology: Human Learning \& Memory, 6, 576-587.

BEGG, I. (1978). Imagery and organization in memory: Instructional effects. Memory \& Cognition, 6, 174-183.

BEGG, I. (1979). Trace loss and the recognition failure of unrecalled words. Memory \& Cognition, 7, 113-123.

BeGG, I., \& AZZARELlo, M. (1988). Recognition and recall of invisible objects. Memory \& Cognition, 16, 327-336.

BegG, I., Maxwell, D., MitTerer, J. O., \& Harris, G. (1986). Estimates of frequency: Attribute or attribution? Journal of Experimental Psychology: Learning, Memory, \& Cognition, 12, 496-508.

BEGG, I., \& SIKICH, D. (1984). Imagery and contextual organization. Memory \& Cognition, 12, 52-59.

BowER, G. H. (1970). Imagery as a relational organizer in associative learning. Journal of Verbal Learning \& Verbal Behavior, 9, 529-533.

Bower, G. H., \& Winzenz, D. (1970). Comparison of associative learning strategies. Psychonomic Science, 20, 119-120.

BURNS, D. J. (1993). Item gains and losses during hypermnesic recall: Implications for the item-specific-relational information distinction. Journal of Experimental Psychology: Learning, Memory, \& Cognition, 19, 163-173.

CLARK, S. E. (1992). Word frequency effects in associative and item recognition. Memory \& Cognition, 20, 231-243.
Clark, S. E., \& Burchett, R. E. R. (1994). Word frequency and list composition effects in associative recognition and recall. Memory $\&$ Cognition, 22, 55-62.

Clark, S. E., \& ShIfFrin, R. M. (1992). Cuing effects and associative information in recognition memory. Memory \& Cognition, 20, 580-598

CoNNOR, J. M. (1977). Effects of organization and expectancy on recall and recognition. Memory \& Cognition, 5, 315-318.

DEMPSTER, R. N., \& RoHWER, W. D. (1974). Component analysis of the elaborative encoding effect in paired-associate learning. Journal of Experimental Psychology, 103, 400-408.

DOSHER, B. A. (1988). Retrieval dynamics of item and associative information. Unpublished manuscript.

DOSHER, B. A. (1991). Bias and discrimination in cuing of memory: A weighted decisions model. In W. E. Hockley \& S. Lewandowsky (Eds.), Relating theory and data: Essays on human memory in honor of Bennet B. Murdock (pp. 249-278). Hillsdale, NJ: Erlbaum.

EINSTEIN, G. O., \& HuNT, R. R. (1980). Levels of processing and organization: Additive effects of individual item and relational processing. Journal of Experimental Psychology: Human Learning \& Memory, 6, 588-598.

Friendly, M., Franklin, P. E., Hoffman, E., \& Rubin, D. C. (1982). The Toronto Word Pool: Norms for imagery, concreteness, orthographic variables, and grammatical usage for 1,080 words. Behavior Research Methods \& Instrumentation, 14, 375-399.

Gillund, G., \& Shiffrin, R. M. (1984). A retrieval model for both recognition and recall. Psychological Review, 91, 1-67.

GLANZER, M., \& ADAMS, J. K. (1985). The mirror effect in recognition memory. Memory \& Cognition, 13, 8-20.

GLANZER, M., \& ADAMS, J. K. (1990). The mirror effect in recognition memory: Data and theory. Journal of Experimental Psychology: Learning, Memory, \& Cognition, 16, 5-16.

Glanzer, M., Adams, J. K., Iverson, G. J., \& Kim, K. (1993). The regularities of recognition memory. Psychological Review, 100, 546567.

Glenberg, A., Smith, S. M., \& Green, C. (1977). Type I rehearsal: Maintenance and more. Journal of Verbal Learning \& Verbal Behavior, 16, 339-352.

Gronlund, S. D., \& RATCLIFF, R. (1989). Time course of item and associative information: Implications for global memory models. Journal of Experimental Psychology: Learning, Memory, \& Cognition, 15, 846-858.

HiNTZMAN, D. L. (1994). On explaining the mirror effect. Journal of Experimental Psychology: Learning, Memory, \& Cognition, 20, 201-205.

HirshmaN, E., \& BJoRK, R. A. (1988). The generation effect: Support for a two-factor theory. Journal of Experimental Psychology: Learning, Memory, \& Cognition, 14, 484-494.

HOCKLEY, W. E. (1991). Recognition memory for item and associative information: A comparison of forgetting rates. In W. E. Hockley \& S. Lewandowsky (Eds.), Relating theory and data: Essays on human memory in honor of Bennet B. Murdock (pp. 227-248). Hillsdale, NJ: Erlbaum.

HoCKLEY, W. E. (1992). Item versus associative information: Further comparisons of forgetting rates. Journal of Experimental Psychology: Learning, Memory, \& Cognition, 18, 1321-1330.

HOCKLEY, W. E. (1994). Reflections of the mirror effect for item and associative recognition. Memory \& Cognition, 22, 713-722.

HuMPHREYS, M. S. (1976). Relational information and the context effect in recognition memory. Memory \& Cognition, 4, 221-232.

HuMPHREYS, M. S. (1978). Item and relational information: A case for context independent retrieval. Journal of Verbal Learning \& Verbal Behavior, 17, 175-187.

Hunt, R. R., \& Einstein, G. O. (1981). Relational and item-specific information in memory. Journal of Verbal Learning \& Verbal Behavior, 20, 497-514.

Hunt, R. R., \& SETA, C. E. (1984). Category size effects in recall: The roles of relational and individual item information. Journal of Experimental Psychology: Learning, Memory, \& Cognition, 10, 454-464.

KLEIN, S. B., Loftus, J., Kinlstron, J. F., \& ASERON, R. (1989). Effects of item-specific and relational information on hyperamnesic recall. Journal of Experimental Psychology: Learning, Memory, \& Cognition, 15, 1192-1197. 
KuČERA, F., \& FranCIS, W. (1967). Computational analysis of presentday American English. Providence, RI: Brown University Press.

LEWANDOWSKY, S., \& LI, S.-C. (1993). Intralist distractors and recall direction: Constraints on models of memory for serial order. Journal of Experimental Psychology: Learning, Memory, \& Cognition, 19, 895-908.

LEWANDOWSKY, S., \& LI, S.-C. (1994). Memory for serial order revisited. Psychological Review, 101, 539-543.

LEWANDOWSKY, S., \& MURDOCK, B. B., JR. (1989). Memory for serial order information. Psychological Review, 96, 25-57.

MARschark, M., \& HUNT, R. R. (1989). A reexamination of the role of imagery in learning and memory. Journal of Experimental Psychology: Learning, Memory, \& Cognition, 15, 710-720.

MAY, R. B., \& SANDE, G. N. (1982). Encoding expectancies and word frequency in recall and recognition. American Journal of Psychology, 95, 485-495.

MCGEE, R. (1980). Imagery and recognition memory: The effects of relational organization. Memory \& Cognition, 8, 394-399.

MuRdock, B. B., JR. (1974). Human memory: Theory and data. Hillsdale, NJ: Erlbaum.

MURDOCK, B. B., JR. (1982). A theory for the storage and retrieval of item and associative information. Psychological Review, 89, 609626.

MURDock, B. B., JR. (1983). A distributed memory model for serialorder information. Psychological Review, 90, 316-338.

MuRDOCK, B. B. (1987). Serial-order effects in a distributed-memory model. In D. S. Gorfein \& R. R. Hoffman (Eds.), Memory and learning: The Ebbinghaus centennial conference (pp. 277-310). Hillsdale, NJ: Erlbaum.

MURDOCK, B. B. (1989). Learning in a distributed memory model. In C. Izawa (Ed.), Current issues in cognitive processes: The Floweree Symposium on Cognition (pp. 69-106). Hillsdale, NJ: Erlbaum.
MURDOCK, B. B. (1992). Item and associative information in a distributed memory model. Journal of Mathematical Psychology, 36, 68-99. MURDOCK, B. B. (1993). TODAM2: A model for the storage and retrieval of item, associative, and serial-order information. Psychological Review, 100, 183-203.

MURDOCK, B. B. (1995, January). Item and associative information in a distributed-memory model. Paper presented at the Twentieth Annual Interdisciplinary Conference, Jackson Hole, Wyoming.

Murdock, B. B., \& HockLEY, W. E. (1989). Short-term memory for associations. In G. H. Bower (Ed.), The psychology of learning and motivation (Vol. 24, pp. 71-108). San Diego, CA: Academic Press.

NeEly, J. H., \& Balota, D. A. (1981). Test-expectancy and semanticorganization effects in recall and recognition. Memory \& Cognition, 9, 283-300.

Paivio, A., Yuille, J. C., \& Madigan, S. A. (1968). Concreteness, imagery, and meaningfulness values for 925 nouns. Journal of Experimental Psychology Monographs, 76(1, Pt. 2), 1-25.

RaAiJMakers, J. G. W., \& Shiffrin, R. M. (1981). Search of associative memory. Psychological Review, 88, 93-134.

REDER, L. M., ANDERSON, J. R., \& BJoRK, R. A. (1974). A semantic interpretation of encoding specificity. Journal of Experimental Psychology, 102, 648-656.

WEBER, E. U. (1988). Expectation and variance of item resemblance distributions in a convolution-correlation model of distributed memory. Journal of Mathematical Psychology, 32, 1-43.

Yonelinas, A., Hockley, W. E., \& Murdock, B. B. (1992). Tests of the list-strength effect in recognition memory. Journal of Experimental Psychology: Learning, Memory, \& Cognition, 18, 345-355.

(Manuscript received November 16, 1994; revision accepted for publication March 17, 1995.) 